Revista Iberoamericana, Vol. LXXV, Núm. 228, Julio-Septiembre 2009, 719-735

\title{
ENTRE LO TRANSATLÁNTICO Y LO HEMISFÉRICO: LOS PROYECTOS RACIALES DE ANDRÉS BELLO
}

\author{
POR \\ RUTH HILL ${ }^{1}$ \\ University of Virginia
}

En la abundante crítica sobre las Silvas americanas de Andrés Bello, la cuestión de la raza brilla por su ausencia. Sus comentarios sobre la historia americana y la europea y sus reseñas de libros, todos publicados en revistas, no han gozado de mejor fortuna. ${ }^{2}$ El presente ensayo tiene por objetivo analizar "La agricultura de la Zona Tórrida” y sus comentarios y reseñas críticas como proyectos precisamente raciales dirigidos a la formación racial de los latinoamericanos en el siglo XIX. Por “formación racial” se entenderá aquí lo que plantean Michael Omi y Howard Winant en un estudio fundacional de la teoría crítica sobre la raza (Critical Race Theory): "el desenlace sociohistórico mediante el cual se crean, se asumen, se transforman y se destruyen las categorías raciales". ${ }^{3}$ Este proceso ocurre "por medio de un eslabonamiento entre la estructura [o clase social] y la representación” (56). De esto se desprende que los proyectos raciales realicen ideológicamente ciertas conexiones: "El proyecto racial es una interpretación, representación o explicación de la dinámica racial y simultáneamente un esfuerzo por reorganizar y redistribuir los recursos según determinados patrones raciales" (Omi y Winant 56). Los proyectos raciales de Bello son contradictorios y cosmopolitas, y nuestro análisis no pretende en absoluto agotar el tema. La formación racial de Hispanoamérica a lo largo del siglo XIX se construyó de proyectos raciales como éstos y de otros más obvios -el mestizaje- y menos obvios -el americanismo-. Por lo tanto, nosotros intentaremos relacionar los proyectos raciales de Bello con otros forjados por

1 Agradezco los comentarios de Teresa Sanhueza a una versión preliminar de este ensayo.

2 Por ejemplo, Iván Jaksic los ve como un puente entre las Silvas y las “obras maestras” de Bello (94). Efraín Kristal ha estudiado el debate historiográfico chileno sobre el papel del indio, el cual involucró a Bello, Domingo F. Sarmiento y José Victorino Lastarria. Mariselle Meléndez analiza las discrepancias entre Lastarria y Bello, sobre todo, y subraya el racismo de Bello en su revisión de la conquista de América. Ningún estudio monográfico ha extendido las agudas observaciones preliminares de Kristal y Meléndez.

3 Todas las traducciones, a menos que se especifique lo contrario, son nuestras. 
contemporáneos suyos, anticipando la futura generación de modelos transnacionales sobre la formación racial en tres núcleos fundamentales: Hispanoamérica, España y Estados Unidos.

En el devenir racial de Bello, identificamos dos fases que corresponden grosso modo a dos transatlanticismos distintos. Por "transatlanticismo" entendemos una perspectiva, subjetividad y/o configuración del complejo de relaciones entre Europa y las Américas, o más estrechamente, entre España e Iberoamérica, que también se triangula e incluye otros puntos focales. Durante su residencia en Londres (18101829) por ejemplo, el transatlanticismo del venezolano compartió algunos de los preceptos ideológicos y literarios de ciertos angloparlantes: un exotismo en el que sobresalen la piña, la selva, la palma, el banano, los esclavos africanos y los letárgicos americanos españoles. A su vuelta a América, el transatlanticismo de Bello sería cultivado por igual entre los anglo- y los hispanoparlantes, y en éste se destacan los españoles, los indígenas y los mestizos en tierras de un clima más variado.

Ese segundo transatlanticismo de Bello estuvo marcado por dos fases principales. Durante la primera, Bello cotejó teorías sobre la raza y el desarrollo social y económico, sin llegar a conclusiones definitivas. Su gran proyecto racial en esa fase fue poner en tela de juicio las afirmaciones de otros respecto a la raza como categoría y a la raza española como fundadora de Iberoamérica. Durante la segunda fase, Bello redujo los elementos no-europeos a uno solo, el indígena, y retrató a los españoles como europeos occidentales o blancos. El principal resultado de esos proyectos raciales fue una formación racial de los latinoamericanos regida por el paradigma indígena-europeo, o sea, el binarismo rojo-blanco. Esta segunda fase terminó cuando Bello proyectó la futura desaparición biológica y cultural del indio en las Américas, logrando reducir así el binarismo a la primacía blanca o caucásica.

PRIMER TRANSATLANTICISMO

El poema más renombrado de Bello, "La agricultura de la Zona Tórrida” (1826), fue publicado por primera vez en una revista y data de su exilio londinense. Si bien sobresalen en esta silva las imágenes de la naturaleza americana, escasean las explícitas alusiones a los habitantes indígenas; solamente hallamos dos hacia el final del poema: “Asaz de nuestros padres malhadados/expïamos la bárbara conquista” (vv. 302-303) y "Saciadas duermen ya de sangre ibera/las sombras de Atahualpa y Motezuma” (vv. 310-311). Ninguna de las dos es encomiástica: los conquistadores españoles parecen haber sido víctimas de los indígenas. ${ }^{4}$ La actitud

\footnotetext{
4 Resulta curioso, entonces, que Miguel Ángel Asturias, al aceptar el Premio Nóbel, hubiera subrayado
} en su discurso ("Latin American Novel”) la plena reivindicación del indio en esta silva de Bello 
del poeta frente al africano, en cambio, se expresa en catorce versos entablados con un topos predilecto de los neoclásicos tropicalistas:

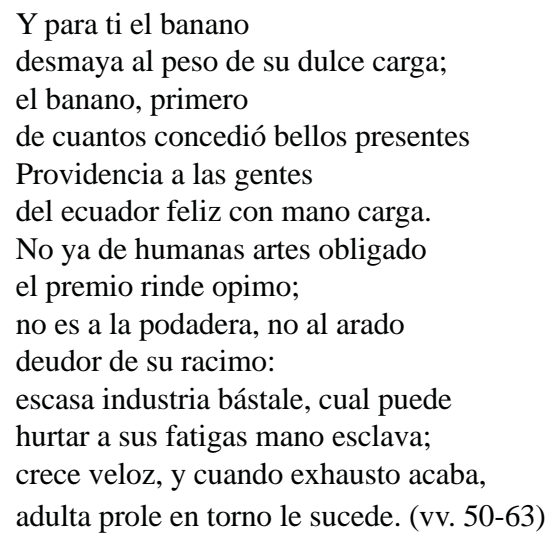

Notemos que las "fatigas" de la "mano esclava" contrastan radicalmente con el ocio del "indolente habitador" (v. 67), de lo cual el lector podría inferir que los africanos son todos esclavos y víctimas de los perezosos iberoamericanos, mientras los indígenas son meros espectros de imperios pasados.

Claro que la comprensión teórica de la raza que subyace en "La agricultura de la Zona Tórrida” no se revela en esos versos. No obstante, las circunstancias biográficas del venezolano nos dan pistas al respecto. Sabemos que en Londres, mientras Bello componía sus Silvas Americanas, determinados tratados demográficos, agrícolas y económicos se difundían y se debatían ampliamente; entre estos, varios publicados por James Mill (padre del filósofo John Stuart Mill), quien, en algún momento, presentó a Bello al utilitarista Jeremy Bentham (véase Rodríguez Monegal, cap. 2; Durán Luzio 85-102; Racine). Éste había hecho el papel de consultor del gobierno español sobre la Constitución durante las Cortes, como lo demuestran sus Letters to Count Toreno (1822). Es probable que una fuerte inspiración para el poema le haya llegado a Bello a través de la Introduction to the Principles of Morals and Legislation (1789) de Bentham. En la más difundida versión española de esta obra (Principios de lejislación), leemos:

Circunstancias secundarias que influyen sobre la sensibilidad. [...] $7^{\circ}$. La casta. Un negro nacido en Francia o Inglaterra es un ser bien diferente, bajo muchos conceptos, de un niño de casta francesa o inglesa. Un niño español nacido en

y en la Rusticatio mexicana de Rafael Landívar. El transformar a esos dos poetas neoclásicos en indigenistas nos parece una tarea bastante difícil aún para un novelista de la talla de Asturias. 
Méjico o en el Perú, es desde el instante de su nacimiento bien diferente de un niño mejicano o peruano. La casta puede influir sobre la capacidad natural, que sirve de base a todo lo demás: en lo sucesivo contribuye muy más sensiblemente al rumbo moral o relijioso que se toma, a las simpatías y antipatías. (65) ${ }^{5}$

Aquí Bentham se refería a los legisladores y a la codificación de los castigos, y ya sabemos que Bello más tarde se mostraría apasionado por los mismos temas (véase, por ejemplo, "Influjo de la civilización en la moralidad”). Esta acepción de raza acompañó a su admirador venezolano al atravesar el oceáno Atlántico e instalarse en Chile.

SEGUNDO TRANSATLANTICISMO: PRIMERA FASE

En el ensayo "Las repúblicas hispano-americanas", publicado en la revista El Araucano en 1836, Bello alude a la que se conoce como la tesis jeffersoniana sobre el excepcionalismo americano y la unidad hemisférica (Whitaker 28-29), pero sin nombrar al virginiano:

No ha faltado quien crea que un considerable número de naciones colocadas en un vasto continente, e identificadas en instituciones y en origen, y a excepción de los Estados Unidos, en costumbres y religión, formarán con el tiempo un cuerpo respetable, que equilibre la política europea, y que por el aumento de riqueza y de población y por todos los bienes sociales que deben gozar a la sombra de sus leyes, den también, con el ejemplo, distinto curso a los principios gubernativos del antiguo continente. (469-70)

La verdad es que ese excepcionalismo ya había echado raíces en la esfera pública venezolana varias décadas antes. En el número del martes 20 de noviembre de 1810 de la Gazeta de Caracas, cuyo “redactor principal” era Bello (Durán Luzio 14, 91), encontramos que las virtudes y el civismo de la América española son contrastados con "la política del otro hemisferio" (f. 1). Desde una óptica transatlántica, y sin saberlo, se formulaba, en este anónimo artículo, la contradictoria agencia deAmérica Latina (y de España, desde luego) dentro del discurso de la modernidad. Así, podemos leer que la misión providencial del Nuevo Mundo era la de redimir a los españoles (a la sazón en garras francesas) y enseñar a los europeos la superioridad moral y política de los americanos (f.1).

5 Para Bentham, de las 32 "circunstancias influyentes sobre la sensibilidad", la 30 (y no 7) era "Linaje” o raza (52). Ya que Bello emplearía "raza” (y no "casta”) en sus escritos, es muy probable que Bello siguiera el texto original de Bentham. 
Bello pronosticó en su ensayo de 1836 (“Las repúblicas hispano-americanas”) que Hispanoamérica iba a lograr la prosperidad a duras penas, debido a su inexperiencia y a la mentalidad colonial de sus repúblicas (470). Pero algunos se mostraban pesimistas, negando "hasta la posibilidad de adquirir una existencia propia a la sombra de instituciones libres que han creído enteramente opuestas a todos los elementos que pueden constituir los gobiernos hispano-americanos" (470). Las opiniones negativas sobre las revoluciones americanas se virtieron en las revistas que Bello solía leer en Londres: Edinburgh Review, Foreign Quarterly Review, etc., y en otras, publicadas en Estados Unidos, que seguramente conocía, como la North American Review. Pero, de los escritores escépticos con respecto a Hispanoamérica, el más contundente era indudablemente Alexis de Tocqueville. Su primer tomo (1835) de De la démocratie en Amérique está marcado por una serie de comparaciones entre Angloamérica e Hispanoamérica nada favorables para esta última. ${ }^{6}$

Bello se limita a resumir los argumentos de los detractores de Hispanoamérica, poniendo de relieve lo que denominamos aquí el "contraste institucional o desarrollista”:

La situación de unos y otros pueblos al tiempo de adquirir su independencia era esencialmente distinta: los unos tenían las propiedades divididas, se puede decir, con igualdad; los otros veían la propiedad acumulada en pocas manos. Los unos estaban acostumbrados al ejercicio de grandes derechos políticos, al paso que los otros no los habían gozado, ni aun tenían idea de su importancia. Los unos pudieron dar a los principios liberales toda la latitud de que hoy gozan, y los otros, aunque emancipados de la España, tenían en su seno una clase numerosa e influyente con cuyos intereses chocaban. Éstos han sido los principales motivos, porque han afectado desesperar de la consolidación de nuestros gobiernos los enemigos de nuestra independencia. (470)

Un tropo historicista que se empleó con gran frecuencia a lo largo del siglo XIX y principios del siglo xx, el contraste institucional o desarrollista pretendía explicar el estado actual de las dos Américas recurriendo a las experiencias y condiciones económicas y políticas a la hora de lograr su independencia.

Esteban Echeverría, por ejemplo, no dudó en proclamar que la herencia española de los hispanomericanos era desastrosa: "Nosotros fuimos parte integrante de la sociedad española [...]. Verdad es que la España, entonces, era la más atrasada de

\footnotetext{
${ }_{6}^{6}$ Tampoco podemos descontar por completo la posibilidad de que Bello ya hubiera leído las Lettres sur l'Amérique du Nord (1836) de Michel Chévalier (1806-1879), un economista francés cuya influencia sobre el jurista americano veremos más adelante; o Voyage pittoresque dans les deux Amériques (1836) del naturalista Alcide Dessalines d’Orbigny (1802-1857).
} 
las naciones europeas, y que nosotros, en punto de luces, nos hallábamos, gracias a su paternal gobierno, en peor estado" ("Discurso" [1837] 202). La revolución "abrió la senda del progreso" a los argentinos, "rompiendo el vasallaje y derribando las murallas que [los] separaban de la Europa civilizada" (202). Esta Europa -es decir: Francia e Inglaterra-, desde luego, ejercía una influencia preponderante en la otra América.

El estadounidense Thomas Bangs Thorpe, citando a Tocqueville y D’Orbigny, concordaba, aseverando que

[l]as repúblicas de México, América Central y Sudamérica, al compararse con la gran república angloamericana, exhiben un chocante contraste en sus aspectos políticos, sociales y morales, en vez de manifestar analogías. Desde luego se pregunta: ¿Qué ha causado esta clara diferencia? ${ }^{7}$ (345)

La respuesta era el "contraste fundacional" derivado de las supuestas diferencias irreducibles entre los diversos colonizadores europeos de las Américas.

Muchas veces se construía una antítesis completamente histórica o teleológica y se articulaba en términos del "capital cultural” o "social”: las respectivas actitudes y capacidades de los ingleses y los españoles en múltiples esferas (la religión, la propiedad privada, la común defensa, los recursos naturales, etc.). ${ }^{8}$ Sin embargo, no escasearon circunstancias en las que el contraste fundacional se revestía de un carácter claramente genealógico o racial. En tales ocasiones, había dos posibles versiones: según la primera los conquistadores españoles, a diferencia de los ingleses, habían sido un pueblo mestizado y, como consecuencia de esto, una población fuertemente mestizada surgía rápidamente en las colonias españolas, y no en las inglesas; mientras la segunda eliminaba la causalidad y sólo sostenía que una mayoría mestizada había surgido en Hispanoamérica y no en Angloamérica. ${ }^{9}$

7 En el original se lee: “The republics of Mexico and of Central and South America, when compared with the great Anglo-American republic, instead of presenting any analogy, exhibit a striking contrast in their political, social, and moral aspects. The question naturally suggests itself, What has produced this marked dissimilarity?"

8 Vale la pena recordar que ese contraste también fue cobrando cuerpo en la formación racial de los brasileños: véase Agassiz, Journey in Brazil (1867), 503.

9 Democracy in America [De la démocratie en Amérique] se suscribe a esta segunda vertiente. A la hora de la conquista o fundación -sostenía Tocqueville- los grupos europeos se relacionaban con los indios de maneras muy distintas: los españoles se mezclaban con los indios mientras los ingleses se mantenían segregados de los nativos. La misma actitud distinguió a los ingleses de los españoles en el ámbito de las relaciones con los africanos y, por lo tanto, abundaban los mulatos en Hispanoamérica (1; cap. 18, passim.). Véase también Wilson, 177-79; Horsman, caps. 11 y 12; Brack, 45; y Robinson, xliii-xlv. 
En otros casos, el contraste fundacional se volvió tan genealógico como histórico. En 1861, por ejemplo, José Samper señalaría la mestización y el capital social como las desventajas de América Latina. Otro ejemplo inequívoco reluciría en Conflicto y armonías de las razas (1883) de Domingo F. Sarmiento. ${ }^{10}$

Nuevamente en las páginas de El Araucano, en "El gobierno y la sociedad" (1843), Bello se mostró interesado en comprender esa fascinación de su siglo por la raza, ahora en términos explícitos y con relación al desarrollo de instituciones democráticas y a la prosperidad económica. Primero, Bello anticipó una de las máximas clave del positivismo de Herbert Spencer, crítico acérbico de Jeremy Bentham (Hofstadter 40), al sostener que el desarrollo social y económico no se podía gestionar desde arriba (283-84). Al hacerlo se refirió a un tema tan transcendental como la misma emancipación americana:

[E]lprincipal agente en la producción de [la prosperidad económica y la democracia] es el espíritu público de los habitantes, favorecido por circunstancias peculiares; tales como (en sentir de algunos) la raza; una antigua educación moral y política, que ha tenido tiempo de echar raíces profundas en las costumbres; la situación geográfica; la fecundidad de producciones naturales ilimitadamente apetecidas por otros pueblos y fácilmente permutables por los productos de la industria extrangera; vías de transporte interior, preparadas en grande escala por la naturaleza misma [...]. (284)

Bello aquí no concretiza ese proléptico "sentir de algunos”, pero sabemos bien lo que la raza no era para él en 1843: no implicaba ni las costumbres, ni la situación geográfica, ni los recursos naturales.

Más adelante, el ensayista procede con una serie de interrogativas bastante sugerentes:

¿Tienen estos medios a su alcance las nuevas repúblicas americanas? ¿Les es dado modificar los efectos profundos y misteriosos de la acción orgánica, que hace, según se dice, tan diferente la fibra anglo-sajona de la céltica o de la ibera? ¿Les es dado variar en un momento las costumbres? ¿Está en sus manos crear,

\footnotetext{
10 “La colonización reservó en España cuanto ésta contenía de más noble y elevado, y creó en Colombia [es decir: Hispanoamérica] una sociedad de aventureros corompidos [sic], o ineptos, o fanáticos, o descamisados, injertada como una planta venenosa en una masa inerte de turbas que vivían bajo la organización del socialismo patriarcal o primitivo. Lo que de tal injerto resultó (sin contar la savia africana) no podía menos que adolecer de todos los vicios y defectos de la sociedad española, sin ninguna de sus cualidades [...]. La herencia española fue, pues, el capital social de los pueblos colombianos" (Samper 262). Véase también Sarmiento, "Amalgama de razas de color diverso" (111-17), donde cita a Wilson y Agassiz (309-11) y (449-55). El capital social es un concepto francés decimonónico actualizado en Estados Unidos por Fukuyama (2000).
} 
donde no los hay, esos instrumentos colosales de engrandecimiento a que deben su acelerado progreso los Estados Unidos [...]? (284)

Estas palabras “según se dice” sacan a relucir un concepto de raza bien difundido en Europa e Hispanoamérica y aun en Angloamérica: las razas europeas o blancas, en plural. Se creía que la raza irlandesa, la anglosajona y la española eran razas distintas. ${ }^{11}$ Como la raza tiene su entrada (aunque proléptica) en este análisis comparativo del desarrollo de las Américas, está claro que Bello conocía ese concepto plural y miraba el contraste fundacional como causa posible de la desigualdad de nivel en el desenvolvimiento económico y político de Angloamérica e Hispanoamérica (ambos en relación a Inglaterra e Iberia respectivamente).

Todo esto, conviene recordar, no elimina en absoluto las ambigüedades de la comprensión teórica de Bello con respecto a la raza. Por un lado, argumenta que la prosperidad -el progreso económico y político- no se puede legislar, como afirmaría más tarde el positivismo spenceriano: "Los sueños dorados y las perspectivas teatrales desaparecen ante las severas, las inflexibles leyes de la materia y del espíritu; leyes que dejan límites harto estrechos a la esfera de acción de los legisladores humanos” (285). La raza (“la acción orgánica” o “la fibra”) era, le constaba al jurista, una de estas leyes “inflexibles”. Por otro lado, haciéndose eco de la Introduction to the Principles of Morals and Legislation de Bentham, Bello insiste en que la raza es sólo una de las muchas "circunstancias naturales y morales" que ha de tener en cuenta el que mira desapasionadamente el estado de las Américas y sus causas en 1843.

Así, Bello concluye en "El gobierno y la sociedad” que las instituciones democráticas se adaptan a todos los pueblos, y defiende esta proposición comparando a dos hombres de regiones distintas de Estados Unidos. Reproduce un exemplum del “célebre escritor” Michel Chévalier (Lettre 10: “L’yankée et le virginien”, 1: 161-85):

\footnotetext{
${ }^{11}$ Véase Ardao, Sección Primera; Jacobson, passim.; Hill, Hierarchy, cap. 5. Según Francisco Bilbao, por ejemplo, América fue conquistada por la raza menos inteligente de toda Europa: "La raza española es inferior en inteligencia a las razas Europeas [...]. La forma de su frente revela más bien la fortaleza de la tenacidad que la habitación de la inteligencia. [...] La España puede tener todas las buenas calidades morales que sus hijos le atribuyan, pero no se puede negar que es la raza europea más limitada en cuanto a su desarrollo intelectual” (344). Una fuente importante para Bilbao (y, más adelante, para Domingo F. Sarmiento) fue Henry Thomas Buckle, cuya Historia de la civilización de Europa recién había llegado a Buenos Aires (Bilbao 347, n. 2). Por otro lado, el chileno Victorino Lastarria (a quien volveremos más tarde) rechazaría esta teorización de "razas europeas”: “¿No hemos visto fundarse diarios y escribir libros para propagar la ridícula teoría de que la raza latina tiene una naturaleza diferente y condiciones contrarias a las de la raza germánica, y que, por tanto, sus intereses y su ventura la fuerzan a buscar su progreso bajo el amparo de los gobiernos absolutos, porque el parlamentario no está a su alcance?” (12-13).
} 
En Baltimore como en Boston, en la Nueva Orleans como en Salem, en la Nueva York como en Portland, si se habla de un comerciante que por bien entendidas combinaciones ha realizado y conservado una ingente fortuna, y preguntáis de dónde es, "es un yanqui”, os responderán. Si en el sur se pasa junto a una plantación que parece mejor cuidada que las otras, con más bellas arboledas, con chozas de esclavos mejor alineadas y más cómodas, "oh! es de un hombre de la Nueva Inglaterra”, oiréis decir [...]. En una aldea del Missouri, al lado de una casa cuyos cristales están hechos pedazos, y a cuya puerta riñen muchachos andrajosos, veis otra casa acabada de pintar, cercada de una reja sencilla y limpia, con una docena de árboles bien chapodados al rededor; y por entre las ventanas alcanzáis a ver [...] una reunión de jóvenes bien peinados [...]. Una y otra son casas de labradores; pero el uno de ellos viene de la Carolina del Norte, y el otro de la Nueva Inglaterra. (287-88)

Más que una curiosidad regionalista norteamericana, la comparación le servía a Bello en 1843 para dilucidar los supuestos caracteres nacionales de los angloamericanos y de los iberoamericanos. Eran miembros de la misma nación, de la misma raza, el yanqui y el sureño, y habían recibido de sus antepasados el mismo capital social y cultural. Sin embargo, cada uno conservaba, celosamente, sus rasgos peculiares. El sureño era franco, poco activo, pródigo, cordial, expansivo, cortés, sentimental, noble; el yanqui era práctico, industrioso, astuto, calculador, moderado, circunspecto, lógico, económico, individualista (287). Desde luego, la raza por sí sola no explicaba el desigual desarrollo de las instituciones y las comunidades en las dos regiones de Estados Unidos. Por lo tanto, según Bello, la raza tampoco podía ser la causa principal del desigual desarrollo en las dos Américas. ${ }^{12}$

Ahora, si el contraste fundacional de tinte genealógico no bastaba para explicar las diferencias entre Angloamérica e Hispanoamérica, ¿dónde se podía buscar la causa? La libertad democrática se adapta a todos los pueblos, a todas las razas, según Bello, pero a ella "no le es dado obrar sino con los dos grandes elementos de todas las obras humanas: la naturaleza y el tiempo" (288).

Cada pueblo tiene su fisonomía, sus aptitudes, su modo de andar; cada pueblo está destinado a pasar con más o menos celeridad por ciertas fases sociales; y por grande y benéfica que sea la influencia de unos pueblos en otros, jamás será posible que ninguno de ellos borre su tipo peculiar y adopte un tipo extranjero [...]. (286)

${ }^{12}$ Si hemos aludido a la problemática relación entre Hispanoamérica y el discurso de la modernidad, a raíz del excepcionalismo americano, vale la pena recordar aquí que el desigual desarrollo en Estados Unidos en el siglo XIX no escapaba a los observadores perspicaces. Sobre la falta de desarrollo económico e intelectual en el Sur de Estados Unidos, véanse los capítulos 9 y 11 de Impending Crisis of the South de Rowan Helper (1857), obra que según muchos precipitó la Guerra de Secesión en Estados Unidos. La idea de este país como modelo de la modernidad es, pues, muy moderna. 
La ley de la historia humana no es, pues, la raza: todos los tipos, todos los pueblos, todas las razas forzosamente pasan por las mismas fases sociales, sólo que no al mismo tiempo.

\title{
SEgUNDO TRANSATLANTICISMO: SEGUNDA FASE
}

En un número de El Araucano de 1844, Bello comentó las Investigaciones sobre la influencia de la conquista y del sistema colonial de los españoles en Chile del historiador liberal José Victorino Lastarria (véase Rodríguez Monegal 361-67; Kristal; Meléndez; Jaksic 134-47). A decir verdad, más bien se dedicó en pocas páginas a exponer una teoría propia sobre el mestizaje cultural que resulta de la mestización biológica, utilizando a Lastarria y su breve obra historiográfica como punto de partida. Bello aún vacilaba entre lo particular y lo universal, entre lo americano y lo europeo, entre lo cultural y lo biológico. A manera de ley de la historia humana, propone lo siguiente sobre las conquistas:

\begin{abstract}
Las ideas de un pueblo se incorporan con las ideas de otro pueblo; y perdiendo unas y otras su pureza, lo que era al principio un agregado de partes discordantes, llega a ser poco a poco un todo homogéneo, que se parecerá bajo diversos aspectos a sus diversos orígenes, y bajo ciertos puntos de vista presentará también formas nuevas. Del choque de ideas diversas nacerá una resultante que se acercará más o menos a una de las fuerzas motrices en la razón de la intensidad con que éstas obren, y de las circunstancias que respectivamente las favorezcan. (167)
\end{abstract}

Todo esto es solamente un preludio para otra proposición a modo de ley universal, ya no de las ideas sino de las razas: "Cuando se mezclan dos razas, la idea de la raza trasmigrante prevalecerá sobre la de la raza nativa, según sea su número comparativo, su vigor moral, y lo más o menos adelantado de su civilización”(167). En dos palabras: la superioridad moral, numérica y cultural determina quiénes vencen y quiénes son vencidos. De inmediato, Bello cruza el océano Atlántico retomando el hilo de las ideas y ofreciéndonos un exemplum basado en desconocidas crónicas medievales sobre los godos en España: "Los bárbaros del Norte dieron un nuevo temple a los degradados habitantes de las provincias romanas, y recibieron en cambio mucha parte de las formas sociales de Roma; a la religión, la lengua y las leyes de ella cedieron poco a poco las de aquellos altaneros y feroces conquistadores” (167). ${ }^{13}$ Luego Bello pone las ideas y las razas en el mismo plano, pero aún sin mencionar el ejemplo concreto del mestizaje y de la historia de los hispanoamericanos: "Pero

${ }_{13}$ Curiosamente, estos tres pasajes de Bello nos recuerdan a Tocqueville (1, cap. 18), a quien le agradaba esta suerte de comparaciones transatlánticas. 
puede suceder también que la discordancia entre los elementos que se acercan sea tal, que una invencible repulsión no les permita penetrarse uno a otro y producir un verdadero compuesto. Se mezclarán tal vez las razas, y se rechazarán entre sí las ideas” (167). Con esta nota bene, ya estamos frente a la principal cuestión racial de los intelectuales en las repúblicas independientes de Hispanoamérica. Dos ideas se destacan: la primera, que algunas razas (no nos ha dicho todavía cuáles) se mezclan biológicamente, pero como no se asimilan, no se integran en una sola raza; la segunda, que en estos casos las ideas -la cultura, las instituciones políticas, la organización económica- no llegan a consolidarse (la inherente inestabilidad del pueblo mestizado sería un credo para muchos intelectuales en las dos Américas de 1850 a 1950).

De nuevo, Bello cruza el Atlántico para traernos otro exemplum desde España:

Así los árabes y los españoles presentaron en el occidente de Europa dos tipos de civilización antipáticos. Prescindiendo de ciertas peculiaridades materiales y puramente exteriores, nada arábigo pudo echar raíz en España: la religión, las leyes, el genio del idioma, el de las artes, el de la literatura, poco o nada tomaron de los conquistadores mahometanos. La cultura arábiga fue siempre una planta exótica en medio del triple compuesto ibero-romano-gótico que ocupaba la Península Ibérica. Era necesario que uno de los dos elementos expulsase o sofocase al otro; la lucha duró ocho siglos; y el estrecho de Hércules fue otra vez surcado por la vencida y proscrita civilización del Islam, destinada en todas partes a dejar por fin el campo a las armas del Occidente y a la Cruz. (167-68)

Esta tesis que podemos denominar "El árabe desapareciente" estuvo vinculada a su convicción, tan diferente a la de muchos contemporáneos suyos en Europa e Hispanoamérica, de que España formaba parte de Europa Occidental; el que el progreso de la humanidad estaba en estrecha relación con Europa y la cristiandad se infiere fácilmente de este pasaje. La tesis de "El árabe desapareciente" claramente separó a Bello de Domingo F. Sarmiento en Argentina, quien expondría la tesis de "El español como árabe”, que se remonta hasta los cartesianos franceses (véase Hill, Sceptres, Introd. y Conc.; Torrecilla 91-110).

Sin embargo, si la ley de la historia dicta que todas las razas pasen por las mismas fases sociales (tal como asentó Bello en 1843), ¿cómo explicar la (supuesta) desaparición en España de todo elemento árabe? ¿Se esfumó su civilización como la presencia africana se esfumaría de Hispanoamérica en la mente del venezolano después de 1826? ¿Estaban fuera de la historia los pueblos no-europeos?

Primero, en el siglo xix todavía estaba por consolidarse el estatus caucasiano del español en Europa, donde hacía siglos que se cuestionaba la europeidad del 
español, y en Latinoamérica, donde ciertos contemporáneos de Bello hacían lo mismo, a través de los contrastes institucional y fundacional, y donde la estructura social (la organización y la distribución de capital) claramente iba perjudicando a todos los que no lograran representarse como españoles/caucasianos/blancos. ${ }^{14}$ Recordemos aquí la definición concisa y precisa de Omi y Winant: "El proyecto racial es una interpretación, representación o explicación de la dinámica racial y simultáneamente un esfuerzo por reorganizar y redistribuir los recursos según determinados patrones raciales" (56). Como proyecto racial, pues, la supresión de la herencia árabe de España aportó algo apreciable a la formación racial ibera. Al mismo tiempo constituyó un aporte significativo a la formación racial hispanoamericana: el delimitar la herencia biológica y cultural de los españoles en Europa a sólo los elementos romanos y godos reforzó el elemento caucasiano o blanco dentro del binarismo rojo-blanco en Hispanoamérica.

Ya hemos visto que Bello estrechó la categoría racial del no-europeo en Hispanoamérica al volver de Europa. Su supresión de la agencia histórica (aunque marginada) de los africanos en Hispanoamérica, la cual sobrevivía en "La agricultura de la Zona Tórrida” (1826), cimentó el elemento indígena o rojo dentro del binarismo rojo-blanco. Esa sustitución de varias razas minoritarias por una sola le permitió establecer que "el otro" a tener en cuenta en los debates sobre la raza en Hispanoamérica era el indígena.

A Bello, en 1844, sólo le faltaba adoptar sin reservas una tesis difundida plenamente en Norteamérica, la de "el indio desapareciente", ${ }^{15}$ para terminar su explicación implícita de la estructura social; es decir: representar a las elites caucasianas de Hispanoamérica como guardianes del progreso y, por lo tanto, como las personas más capaces de ejercer el poder político y manejar los recursos económicos. De ahí que Bello deje atrás a "los españoles reaparecientes” después de la Reconquista de España y nos presente a "los indios desaparecientes” después de la Conquista de América:

En la América, al contrario, está pronunciado el fallo de destrucción sobre el tipo nativo. Las razas indígenas desaparecen, y se perderán a la larga en las colonias de los pueblos trasatlánticos, sin dejar más vestigios que unas pocas palabras

${ }^{14}$ Bello no fue el único ni el primer intelectual hispanoamericano que trató de extirpar al árabe de España y hacer del español un caucasiano o blanco. "Pertenecemos a una raza privilegiada [Echeverría recuerda a sus coetáneos intelectuales en 1837] a la raza caucasiana, mejor dotada que ninguna de las conocidas, de un cráneo extenso y de facultades intelectuales y perceptivas” (“Segunda Lectura”, 212).

15 Bastante se ha escrito sobre este lugar común de la literatura y la política norteamericanas. Una excelente introducción al tema se encuentra en Dippie, Vanishing American, Pt. I: “And Then There Were None". 
naturalizadas en los idiomas advenedizos, y monumentos esparcidos a que los viajeros curiosos preguntarán en vano el nombre y las señas de la civilización que les dio el ser. $(168)^{16}$

Bello daba por sentado que los indios iban a desaparecer completamente frente a la civilización superior que habían forjado los de "la raza trasmigrante fundadora" (168).

No es sorprendente, entonces, que en su discusión de la emancipación de Hispanoamérica omita la participación de todos los no-europeos y se niegue drásticamente a aceptar la premisa criollista y americanista de que la emancipación tratara de diferencias culturales o raciales (168). Según Bello, fue el elemento caucasiano, el ibero, lo que aseguró el triunfo americano sobre los "iberos transatlánticos” o españoles europeos (169). En ningún momento hace mención a legiones de soldados pardos, negros, mulatos, indios o mestizos. Los españoles americanos, los caucasianos, son la raza que pertenece a la historia y los agentes históricos de la emancipación americana.

Sin embargo, Bello seguía pensando en la raza, más de lo que quería revelar directamente a los lectores de El Araucano. Termina su reseña con dos preguntas retóricas sobre el mestizaje y las revoluciones en Hispanoamérica:

¿Hay en las razas una complexión peculiar, una idiosincrasia, por decirlo así, indestructible? Y ya que la raza española se ha mezclado con otras razas en América, ¿no sería posible explicar hasta cierto punto por la diversidad de la mezcla las diversidades que presenta el carácter de los hombres y de la revolución en las varias provincias americanas? He aquí un problema que merecería resolverse analíticamente, y en que no nos es posible detenernos [...]. (170)

Para mediados del siglo, los contrastes de lo fundacional/ genealógico (o sea biocultural) y lo institucional/desarrollista le resultaban a Bello verdades posibles. Recordemos cómo había comenzado esta "reseña”: "Pero puede suceder también que la discordancia entre los elementos que se acercan sea tal, que una invencible repulsión no les permita penetrarse uno a otro y producir un verdadero compuesto. Se mezclarán tal vez las razas, y se rechazarán entre sí las ideas” (167). Para entonces, ya le parecía claro a Bello que la mestización había diluido el elemento ibérico; que los elementos discordes simplemente no se habían integrado ni aun "las ideas" (como la libertad, el civismo, la democracia).

Dijimos al comienzo que el primer transatlanticismo de Bello compartió el exotismo ideológico y literario de algunos de sus contemporáneos europeos,

${ }^{16}$ Aquí, una vez más, se perciben fuertes ecos de Tocqueville (1, cap. 18). 
exaltando la naturaleza tropical y destacando al abusado esclavo africano y al perezoso hispanoamericano. Además, especulamos que el concepto deraza de Jeremy Bentham -un concepto biocultural- ejerció una considerable influencia sobre el joven poeta de "La agricultura de la Zona Tórrida”. Al volver a América, Bello de ninguna manera se olvidó de sus lecciones londinenses, pero su transatlanticismo cobró un carácter intensamente hemisférico. Dividimos el segundo transatlanticismo de Bello en dos fases o momentos claves. Hemos visto que el proyecto racial de la primera fase consistió en comprender la raza en su acepción universal e indagar la trayectoria de la misma en la historia de las Américas. En la segunda fase, Bello redujo los elementos americanos no-europeos en uno sólo (el indígena) y retrató a los españoles como europeos/blancos/caucasianos. El principal resultado de esos proyectos raciales fue una formación racial de los latinoamericanos regida por el binarismo rojo-blanco. También hemos analizado cómo Bello proyectó la futura aniquilación del indígena en las Américas para justificar la dominación económica y política caucasiana en Hispanoamérica.

Los proyectos raciales de Andrés Bello representan significativos aportes olvidados a la formación racial latinoamericana en el siglo xIx. El posterior americanismo, al igual que el mestizaje (Martínez Echazábal; Muteba Rahier), fue una narrativa totalizante y reductiva de la modernidad fundida orgánicamente con la hegemonía. En los términos de nuestro análisis, ambos fueron categóricos proyectos raciales: al abogar por una cultura "americana" o "mestiza” o "mulata", los intelectuales no abandonaban el poder de definir la cultura ni los políticos criollos abandonaban el poder de distribuir entre sí los recursos. Los proyectos raciales de los dos transatlanticismos de Bello quedan como reliquias del futuro, de la formación racial todavía en pie en una buena parte de América Latina.

\section{BiBLIOGRAFÍA}

Agassiz, Louis. A Journey in Brazil. 8 ed. Boston: Fields, Osgood \& Co., 1871. Ardao, Arturo. América latina y la latinidad. México: Universidad Nacional Autónoma de México, 1993.

Asturias, Miguel Ángel. “The Latin American Novel: Testimony of An Epoch” [1967]. Nobelprize.org. 25 mayo $2007<$ http://www.nobelprize.org/literature/ laureates/1967/asturias-lecture.html $>$

Bello, Andrés. "La agricultura de la Zona Tórrida". Obras completas de Andrés Bello: Poesías. Fernando Paz Castillo, prol. La Comisión Editora. introd. Caracas: Ministerio de Educación, 1952. 65-74.

“El gobierno i la sociedad”. Obras completas de Don Andrés Bello. Vol. 8. Santiago: Pedro G. Ramírez, 1885. 283-288. 
"Influjo de la civilización en la moralidad (Extracto de la obra Systéme Pénitentiaire en Europe, por M. Cárlos Lucas)”. Obras completas de Don Andrés Bello. Miscelánea. Vol. 15. Santiago: Imprenta Cervantes, 1893. 47-61.

"Investigaciones sobre la influencia de la conquista y del sistema colonial de los españoles en Chile”. Memoria presentada a la Universidad en la sesión solemne de 22 de setiembre de 1844 por Don José Victorino Lastarria. Obras completas. Temas de Historia y Geografía. Vol. 19. Mariano Picón Salas, prol. Caracas: Ministerio de Educación, 1957. 153-73.

"Reflexiones sobre las causas morales de las convulsiones interiores de los nuevos estados americanos i exámen de los medios eficaces para reprimirlas por Don José Ignacio Gorriti, arcediano de la santa iglesia catedral de Salta”. Obras completas de Don Andrés Bello. Vol. 7. Santiago: Pedro G. Ramírez, 1884. 451-73.

"Las repúblicas hispano-americanas". Obras completas de Don Andrés Bello. Vol. 7. Santiago: Pedro G. Ramírez, 1884. 469-73.

Bentham, Jeremy. An Introduction to the Principles of Morals and Legislation. J. H. Burns y H. L. A. Hart, eds. F. Rosen, introd. Oxford: Clarendon Press, 1996.

Principios de lejislación. Tratados de lejislación civil y penal escritos por Jeremías Bentham y traducidos con comentarios por Don Baltasar Anduaga Espinosa. Vol. 1. [14 vols.] Madrid: Oficina del Establecimiento Central, 1841-45.

Letters to Count Toreno on the Proposed Penal Code Delivered in by the Legislation Committee of the Spanish Cortes, April 25, 1821. Londres: R. and A. Taylor, 1822.

Bilbao, Francisco. El Evangelio Americano. Obras completas. Vol. 2. Manuel Bilbao, ed. Buenos Aires: Imprenta de Buenos Aires, 1865. 311-444.

Brack, Gene M. Mexico Views Manifest Destiny, 1821-1846: An Essay on the Origins of the Mexican War. Albuquerque: U of New Mexico P, 1975.

Chévalier, Michel. Lettres sur L’Amérique du Nord. 2 vols. París: Librairie de Charles Gosselin, 1836.

Dippie, Brian W. The Vanishing American: White Attitudes and U.S. Indian Policy. Middletown: Wesleyan UP, 1982.

D’Orbigny, Alcide Dessalines. Voyage pittoresque dans les deux Amériques. Paris: L Tenré, 1836.

Durán Luzio, Juan. Siete ensayos sobre Andrés Bello, el escritor. Santiago: Editorial Andrés Bello, 1999.

Echeverría, Esteban. "Discurso de introducción a una serie de lecturas pronunciadas en el Salón Literario en setiembre de 1837”. Obras completas de Esteban Echeverría. Vol. 1. Juan María Gutiérrez, ed. Buenos Aires: Ediciones Antonio Zamora, 1951. 198-211. 
"Segunda Lectura”. Obras completas de Esteban Echeverría. Vol. 1. Juan María Gutiérrez, ed. Buenos Aires: Ediciones Antonio Zamora, 1951. 21118.

Fukuyama, Francis. “Social Capital”. Culture Matters. Lawrence Harrison y Samuel Huntington, eds. Nueva York: Basic Books, 2000. 98-111.

Gazeta de Caracas 7 (martes 20 de noviembre de 1810).

Hill, Ruth. Hierarchy, Commerce, and Fraud in Bourbon Spanish America: A Postal Inspector's Exposé. Nashville: Vanderbilt UP, 2005.

Sceptres and Sciences in the Spains: Four Humanists and the New Philosophy, ca. 1680-1740. Liverpool: Liverpool UP, 2000.

Hofstadter, Richard. Social Darwinism in American Thought. Eric Foner, introd. Boston: Beacon Press, 1992.

Horsman, Reginald. Race and Manifest Destiny: The Origins of American Racial Anglo-Saxonism. Cambridge y Londres: Harvard UP, 1981.

Jacobson, Matthew Frye. Whiteness of a Different Color: European Immigrants and the Alchemy of Race. Cambridge y Londres: Harvard UP, 1998.

Jaksic, Iván. Andrés Bello: Scholarship and Nation-Building in Nineteenth-Century Latin America. Nueva York: Cambridge UP, 2001.

Kristal, Efraín. “Dialogues and Polemics: Sarmiento, Lastarria, and Bello”. Sarmiento and His Argentina. Joseph T. Criscenti, ed. Boulder y Londres: Lynne Rienner Publishers, 1993. 61-70.

Lastarria, José Victorino. La América. Vol. 1. Madrid: Editorial-América, s.d.

Martínez Echazábal, Lourdes. "Mestizaje and the Discourse of National/Cultural Identity, 1845-1959”. Latin American Perspectives 25/3 (1998): 21-42.

Meléndez, Mariselle. “Miedo, raza y nación: Bello, Lastarria y la revisión del pasado colonial”. Revista Chilena de Literatura 52 (1998): 17-30.

Muteba Rahier, Jean. "Introduction: Mestizaje, Mulataje, Mesticagem in Latin American Ideologies of National Identities”. Journal of Latin American Anthropology 8/1 (2003): 40-51.

Omi, Michael y Howard Winant. Racial Formation in the United States from the 1960s to the 1990s. 2 ed. Nueva York y Londres: Routledge, 1994.

Racine, Karen. "Nature and Mother: Foreign Residence and the Evolution of Andrés Bello’s American Identity, London 1810-1829”. Strange Pilgrimages: Exile, Travel, and National Identity in Latin America, 1800-1990s. Ingrid Fey y Karen Racine, eds. Wilmington: SR Books, 2000. 3-20.

Robinson, Cecil, ed. The View from Chapultepec: Mexican Writers on the MexicanAmerican War. Cecil Robinson, trad. Tucson: U of Arizona P, 1989.

Rodríguez Monegal, Emir. El otro Andrés Bello. Caracas: Monte Ávila Editores, 1969. 
Rowan Helper, Hinton. The Impending Crisis of the South: How to Meet It. Earl Schenck Miers, introd. Nueva York: Collier Books, 1963.

Samper, José M. Ensayo sobre las revoluciones políticas y la condición social de las repúblicas colombianas (Hispano-Americanas). Bogotá: Universidad Nacional de Colombia-Dirección de Divulgación Cultural, 1969.

Sarmiento, Domingo F. Conflictoy armonías de las razas en América. José Ingenieros, introd. Buenos Aires: La Cultura Argentina, 1915.

Thorpe, Thomas Bangs. A Voice to America, or, The Model Republic, Its Glory, or Its Fall, with A Review of the Causes of the Decline and Failure of the Republics of South America, Mexico, and of the Old World Applied to the Present Crisis in the United States. 2 ed. Nueva York: Edward Walker, 1855.

Tocqueville, Alexis de. Democracy in America. Henry Reeve, trad. John C. Spencer, prol. 2 vols. Nueva York: George Dearborn \& Company, 1838.

Torrecilla, Jesús. España exótica. La formación de la imagen española moderna. Boulder: Society of Spanish and Spanish-American Studies, 2004.

Whitaker, Arthur P. The Western Hemishpere Idea: Its Rise and Decline. Ithaca y Londres: Cornell UP, 1969.

Wilson, Robert Anderson. A New History of the Conquest of Mexico in Which Las Casas' Denunciations of the Popular Historians of That War Are Fully Vindicated. Filadelfia: James Challen \& Son, 1859. 